EPITHELIAL CELL BIOLOGY

\title{
Reparative properties of a commercial fish protein hydrolysate preparation
}

\author{
A J Fitzgerald, P S Rai, T Marchbank, G W Taylor, S Ghosh, B W Ritz, R J Playford
}

Gut 2005;54:775-781. doi: 10.1136/gut.2004.060608

See end of article for authors' affiliations .....................

Correspondence to: Professor R J Playford, Department of Gastroenterology, Imperial College Faculty of Medicine, Hammersmith Hospital, Ducane Rd, London W12 ONN, UK; r.playford@ imperial.ac.uk

Revised version received 5 January 2005

Accepted for publication 10 January 2005
Background: A partially hydrolysed and dried product of pacific whiting fish is currently marketed as a health food supplement to support "intestinal health". However, there has been only limited scientific study regarding its true biological activity.

Aims: We therefore tested its efficacy in a variety of models of epithelial injury and repair.

Methods: Effects on proliferation were determined using $\left[{ }^{3} \mathrm{H}\right]$ thymidine incorporation into epithelial rat intestinal RIE-1 and human colonic HT29 cells. Effects on restitution (cell migration) were analysed using wounded HT29 monolayers and its ability to influence gastric injury analysed using a rat indomethacin restraint model. Partial characterisation of bioactive agents was performed using mass spectroscopy, high pressure liquid chromatography, and gas chromatography.

Results: Both cell proliferation and cell migration were increased by about threefold when added at $1 \mathrm{mg} / \mathrm{ml}(\mathrm{p}<0.01)$. Gastric injury was reduced by $59 \%$ when gavaged at $25 \mathrm{mg} / \mathrm{ml}(\mathrm{p}<0.05)$, results similar to using the potent cytoprotective agent epidermal growth factor at $12.5 \mu \mathrm{g} / \mathrm{ml}$. The vast majority of biological activity was soluble in ethanol, with glutamine in its single, di-, and tripeptide forms probably accounting for approximately $40 \%$ of the total bioactivity seen. Fatty acid constituents may also have contributed to cell migratory activity.

Conclusions: Fish protein hydrolysate possesses biological activity when analysed in a variety of models of injury and repair and could provide a novel inexpensive approach for the prevention and treatment of the injurious effects of non-steroidal anti-inflammatory drugs and other ulcerative conditions of the bowel. Further studies appear justified.
$\mathrm{N}$ atural medicinal products have been used for millennia for the treatment of multiple ailments. Although many have been superseded by conventional pharmaceutical approaches, there is currently a resurgence of interest in the use of natural bioactive products by the general public, with many healthy subjects and patients taking them for the prevention and treatment of multiple conditions, including gastrointestinal disorders. ${ }^{1}$ Unfortunately, current evidence of the scientific validity of many of these traditional and commercial compounds is severely limited.

Fermentation is a commonly used process in the standard food industry as well as in the bioactive food (nutriceutical) field. Fermented food products include those derived from milk (yogurt, cheese, kefir), soy (natto, miso), fruits (wine), vegetables (sauerkraut), and fish and meats. All have been consumed for centuries for their nutritional or medicinal properties. ${ }^{2}$ Fermentation of fish and meat was introduced as a means of preservation, and fish sauces and pastes are staples or condiments in Southeast Asian, Scandinavian, and Eskimo cultures. Fermentation of food products has many effects, including partial degradation of protein constituents which, as well as aiding absorption from the gut, may also influence its biological activity.

In the current study, we examined the potential bioactivity of a fermented fish product, commercially available, that is derived from the controlled proteolytic yeast fermentation of pacific whiting (Merluccius productus) and which is claimed to be beneficial for a variety of gut conditions. Although this product is claimed to influence intestinal integrity, the data on which it is based are severely limited, qualitative, and not properly controlled. We have therefore performed a series of studies to analyse this product for potential biological activity with regard to mechanisms of gut integrity and repair using well validated in vitro and in vivo models.

\section{MATERIALS AND METHODS}

All chemicals were purchased from Sigma (Poole, Dorset, UK) unless otherwise stated.

\section{Ethics}

All animal experiments were approved by the Imperial College School of Medicine Animals Ethics Committee and covered by the appropriate licences under the Home Office Animals Procedures Acts, 1986.

\section{Hydrolysed fish protein concentrate}

The dried fish protein hydrolysate preparation studied, Seacure, was donated by Proper Nutrition, Inc. (Reading, Pennsylvania, USA). The raw material for this product, pacific whiting or hake (Merluccius productus), is obtained off the coast of the Pacific Northwest of the USA and British Columbia, Canada. The fish are cleaned, filleted, and minced. The 18-24 hour fermentation process requires 10\% fermentable carbohydrate (as sucrose) by weight in relation to fish mince, $20 \%$ demineralised water, and $0.2 \%$ proprietary proteolytic Hansenula yeast culture. Following fermentation, $0.2 \%$ oleoresin of rosemary (Kalsec, Kalamazoo, Indiana, USA) is added as an antioxidant to stabilise lipids. The ferment is then pasteurised at $80^{\circ} \mathrm{C}$ for 20 minutes and finally spray dried to a fine powder.

The fish protein hydrolysate contains $75-80 \%$ protein constituents $(60 \%$ peptides and $40 \%$ amino acids; data obtained from Tektagen, King of Prussia, Pennsylvania, USA). The major amino acid constituents of this product are glutamine (approximately $14-16 \%$ of total),

Abbreviations: DMEM, Dulbecco's modified Eagle's medium; EGF, epidermal growth factor; HPLC, high pressure liquid chromatography; PBS, phosphate buffer solution; BSA, bovine serum albumin 
asparagine $(10 \%)$, and lysine $(10 \%)$ (data obtained from Eurofins, Memphis, Tennesse, USA). The combined contribution of branched chain amino acids (lysine, leucine, and isoleucine) comprise $23 \%$ of the total amino acid content. This product also contains approximately $6-10 \%$ fish oils which comprise approximately $20 \%$ saturated fatty acids (primarily 16:0), 40\% monounsaturates (16:1 n-7 and 18:1 n-9), and 40\% polyunsaturates (20:5 n-3 and 22:6 n-3), and low levels of phospholipids (data obtained from National Marine Fisheries Service, Charleston, South Carolina, USA).

\section{Study series A: effect of the fish protein hydrolysate on in vitro models of repair Background to methods}

One of the earliest biological repair responses following injury to tissue cells is migration of surviving cells over the denuded area caused by the injury to re-establish epithelial integrity. As it is extremely difficult to study this effect on organ tissue inside a human or animal, cell culture models are commonly used as surrogate markers of this promigratory response. About 24 hours after the injury has occurred, there is also an increase in the rate of cell division in order to re-establish a normal mucosa. Cell culture models have traditionally been also used as surrogate markers for this proliferation response, and because thymidine is a natural constituent of DNA, $\left[{ }^{3} \mathrm{H}\right]$ thymidine incorporation is commonly used as a marker of proliferation. Cells that are actively dividing will therefore increase their uptake of thymidine in the preparatory state of cell division.

\section{Cell migration as a model of wound repair}

Cell migration assays were performed using our previously published methods. ${ }^{3}$ Briefly, HT29 cells were grown to confluence in six well plates in medium consisting of Dulbecco's modified Eagle's medium (DMEM) containing $10 \%$ fetal calf serum at $37^{\circ} \mathrm{C}$ in $5 \% \mathrm{CO}_{2}$ and were then serum starved for 24 hours. Monolayers were then wounded by scraping a disposable pipette tip across the dishes, washed with fresh serum free medium, and cultured in serum free medium in the presence of fish hydrolysate or BSA (control solution to examine non-specific protein effects) at various concentrations up to $1.0 \mathrm{mg} / \mathrm{ml}$. Additional monolayers containing fish hydrosylate at $1 \mathrm{mg} / \mathrm{ml}$ also had the proliferation inhibitor, mitomycin $\mathrm{C}$, added at $0.5 \mu \mathrm{g} / \mathrm{ml}$ in order to examine whether wound closure was dependant on cell proliferation. The rate of movement of the anterior edges of the wounded monolayers was then determined by taking serial photomicrographs at various times after wounding. ${ }^{3}$ An inverted microscope (Nikon TS100) and a Nikon Coolpix 800 digital camera with 125 -fold magnification were used to obtain photomicrographs. Identical regions were examined at each time point by pre-marking the base of the plates to facilitate alignment. Twenty measurements per field were performed by placing a transparent grid over the photograph and measuring the distance moved from the original wound line. All results are expressed as the mean (SEM) of three separate experiments.

\section{Cell proliferation}

Cell proliferation assays were performed using our previously published methods. ${ }^{4}$ Briefly, rat intestinal epithelial (RIE-1) cells and human colonic carcinoma (HT29) cells were grown in DMEM containing glutamine and $10 \%$ fetal calf serum. Effects of fish hydrolysate and epidermal growth factor (EGF, positive control) were subsequently tested under serum starved conditions. To assess the rate of cells entering DNA synthesis, $\left[{ }^{3} \mathrm{H}\right]$ thymidine $(2 \mu \mathrm{Ci} /$ well $)$ was included 24 hours after addition of the test factors and cells were left for a further 24 hours. For each condition, the stimulatory or inhibitory effects of the solutions were measured in quadruplet in six separate wells. Cell viability, determined by the ability to exclude $0.2 \%$ trypan blue, was greater than $90 \%$ in both RIE-1 and HT29 cell lines.

\section{Study series B: stability of the bioactivity of the fish protein hydrolysate in acid/pepsin in vitro Background to method}

Although products may be shown to possess biological activity against cells in vitro, it is important to remember that once ingested, they come into contact with the harsh environment of the stomach acid and proteolytic enzymes which can result in partial or complete abolition of activity. In order to examine this possibility, the bioactive factor was preincubated in conditions mimicking those found in the stomach prior to subsequent analysis in the cell migration assay.

\section{Method}

A stock solution of fish protein hydrolysate was made at a concentration of $10 \mathrm{mg} / \mathrm{ml}$ by dissolving in phosphate buffer solution (PBS). Four aliquots of the fish protein solution were randomised to be incubated in either PBS ( $\mathrm{pH} 5.3$, the $\mathrm{pH}$ of dissolved fish powder) or $0.1 \mathrm{M} \mathrm{HCl}$, each containing pepsin at 5000 units $/ \mathrm{ml}$ for one hour at $37^{\circ} \mathrm{C}$. At the end of the incubation period, all samples were neutralised using $0.1 \mathrm{M} \mathrm{NaOH}$, and all test factors underwent a $1: 10$ dilution in DMEM to a final concentration of $1.0 \mathrm{mg} / \mathrm{ml}$. These solutions were then used to assess the rate of cell migration in the wounded monolayer assay system described earlier.

\section{Study series C: effect of the fish protein hydrolysate on an in vivo rat gastric damaging model \\ Background to method}

Although cell culture studies provide valuable information regarding potential bioactivity, additional information may also be gained by extending studies to the in vivo situation. The ability of the fish protein hydrolysate to prevent gastric damage in rats stressed by indomethacin and restraint was therefore also assessed using a well validated model. ${ }^{35}$

\section{Method}

Male Sprague Dawley rats (225-275 g; Harlan Olac Ltd, UK) were housed in standard cages (four animals per cage) and fed standard laboratory chow (Special Diet Services, Essex, UK) and tap water ad libitum.

Rats were randomised to receive, by gastric gavage, one of the following: $2 \mathrm{ml}$ of saline alone (containing BSA $0.2 \mathrm{mg}$ / $\mathrm{ml}$ ), or varying concentrations of fish hydrolysate in saline at a concentration of $5 \mathrm{mg} / \mathrm{ml}$ or $25 \mathrm{mg} / \mathrm{ml}$, or a protein standard (BSA) also at a concentration of $25 \mathrm{mg} / \mathrm{ml}$. An additional group was given EGF $(12.5 \mu \mathrm{g} / \mathrm{ml})$ as a positive control. As in previous studies using this model, all solutions also contained $2 \%$ hydroxymethyl-propylcellulose to reduce the rate of gastric emptying.

Thirty minutes after gavage, all rats received indomethacin (20 mg/kg subcutaneously) and were placed in Bollman-type restraint cages. Animals were killed three hours later and their stomachs removed, the $\mathrm{pH}$ of the stomachs was measured, and then the stomachs were inflated with $4 \mathrm{ml}$ of $10 \%$ formalin. The stomachs were randomly coded and macroscopic and microscopic assessments of injury were assessed in a blinded fashion. Macroscopic injury was assessed using a dissecting microscope $(\times 10)$ with the aid of a reference square grid and reported as the total area of 

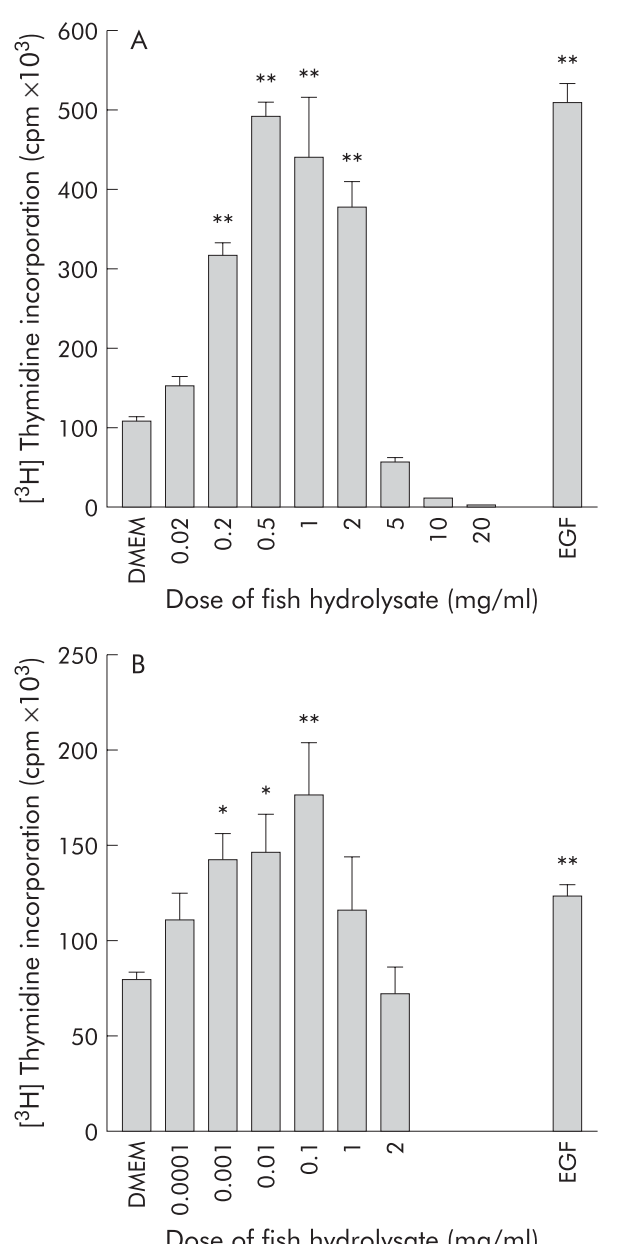

Figure 1 Proliferative responses of HT29 (A) and RIE-1 (B) cells after incubating with various doses of the fish hydrolysate. Proliferation was assessed using $\left[{ }^{3} \mathrm{H}\right]$ thymidine incorporation. Data are presented as mean (SEM); ${ }^{*} p<0.05,{ }^{* *} p<0.01$ versus values found in control wells (incubated in Dulbecco's modified Eagle medium (DMEM) medium alone). In both cell lines, typical "bell-shaped" dose-responses were seen. Additional cells, incubated with $10 \mu \mathrm{g} / \mathrm{ml}$ of epidermal growth factor (EGF), were used as a positive control.

ulceration per stomach $\left(\mathrm{mm}^{2} /\right.$ stomach $)$. The stomachs were then embedded in wax and the depth of damage assessed microscopically, as previously described. ${ }^{5}$ Briefly, microscopic injury was graded with a score from 0 to 4 where $0=$ no damage, $1=$ one small erosion $(<0.5 \mathrm{~mm}), 2=$ two small or one large erosion $(>0.5 \mathrm{~mm}), 3=$ two or more large erosions, and $4=$ any area of ulceration extending to the muscularis mucosa.

\section{Study series $D$ : investigation into active constituents within the fish protein hydrolysate Background to method}

The fish protein hydrolysate contains multiple constituents which may contribute to any bioactivity seen. In order to begin to examine which are the key factors, we examined whether the biological activity was transferable into an ethanol phase, and following this procedure further analysed the active fraction using mass spectroscopy. In addition, as the fish hydrolysate is relatively rich in the amino acid glutamine, we analysed the effect of adding glutamine or a control amino acid, in similar amounts to those found in the fish hydrolysate, to the cell culture systems.
Ethanol extraction of fish protein hydrolysate and cell migration assay

To begin to examine the identity of the bioactive ingredients, the ability of its biological activity to be soluble in ethanol was determined. Fish powder was dispersed in ice cold 100\% aqueous ethanol (solid to liquid ratio $1: 10, \mathrm{~g} / \mathrm{ml}$ ) in a flat bottomed flask, stirred on ice for three hours. The ethanol extracts (soluble substances) and ethanol insoluble substances as residues were separated by decantation. Samples were dried on a centrifugal evaporator and resuspended in DMEM back to the original volume. These solutions were then used to assess the rate of cell migration after fish hydrolysate ethanol extraction in the wounded monolayer assay system, as described above.

\section{HPLC mass spectrometry}

The ethanolic extract was examined for polar components using high pressure liquid chromatography (HPLC) positive ion mass spectrometry. A sample of the ethanolic extract was chromatographed using a Jasco HPLC system on a Hichrom rpb column $(10 \mathrm{~cm} \times 2 \mathrm{~mm}$ id). A 45 minute linear gradient of acetonitrile:water:formic acid (10:90:0.0180:20:0.01) was applied, eluting at $0.3 \mathrm{ml} / \mathrm{min}$. The solvent flow was directed through a diode array UV absorbance monitor (Jasco) and split $1: 13$ into the electrospray ion source of a Micromass Quattro II triple quadrupole mass spectrometer operated in the positive ion mode. Nitrogen was used as the nebulising and drying gas. Source temperature was set at $75^{\circ} \mathrm{C}$ with a cone voltage of $20 \mathrm{~V}$. One second scans were acquired from m/z 150-1100 throughout the HPLC run.

\section{Gas chromatography electron impact mass spectrometry}

The ethanolic extract was examined for lipophilic components using gas chromatography electron impact mass spectrometry. Briefly, a sample of the ethanol extract was esterified with ethereal diazomethane (30 minutes) followed by treatment with bistrimethylsilyl trifluoroacetamide ( 18 hours, room temperature). Excess reagents were removed under a stream of nitrogen. The derivatised sample was dissolved in decane for analysis by capillary gas chromatography mass spectrometry using a VG Trio 1000. The sample was chromatographed on a $25 \mathrm{~m}$ DBl701 column using helium as carrier gas and a temperature gradient of $5^{\circ} \mathrm{C} / \mathrm{min}$ from $150^{\circ}$ to $300^{\circ} \mathrm{C}$. The injector was operated in the splitless mode and the temperature was set at $250^{\circ} \mathrm{C}$. The gas chromatography column was routed into the electron impact ion source of the mass spectrometer. The source temperature was set at $200^{\circ} \mathrm{C}$ and electron energy at $70 \mathrm{eV}$. One second scans were obtained between m/z 70-700.

\section{Effect of glutamine on cell migration}

Cell migration assays were performed as described earlier. Wells contained DMEM alone (negative control), the fish hydrolysate at a final concentration of $1 \mathrm{mg} / \mathrm{ml}$ (this dose was chosen as it gave maximal response), glutamine at $143 \mu \mathrm{g} / \mathrm{ml}$ ( $1 \mathrm{mmol} / \mathrm{l}$, providing a similar amount of total glutamine as that found in the fish hydrolysate when used at $1 \mathrm{mg} / \mathrm{ml}$ ), and glycine at an identical molarity.

\section{Statistics}

All values are expressed as mean (SEM). One or two way ANOVA was used as appropriate. Where a significant effect was seen $(p<0.05)$, individual comparisons were performed using $t$ tests based on group means, residual and degrees of freedom obtained from the ANOVA, a method equivalent to repeated measures analyses. 

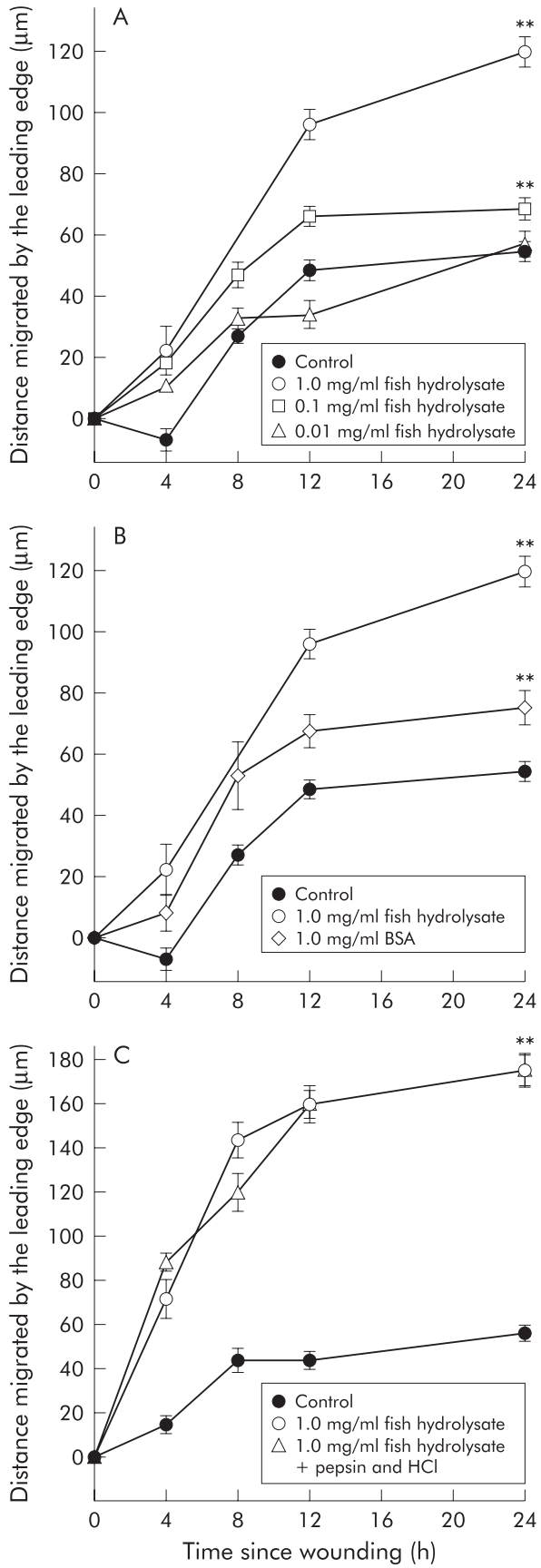

Figure 2 Effect of fish hydrolysate on the rate of cell migration using an in vitro model of wound repair. HT29 cells were grown as a monolayer and a standard wound inflicted at time zero. The distance moved by the leading edge was then determined using serial photomicrographs. When added at concentrations above $0.1 \mathrm{mg} / \mathrm{ml}$, addition of the fish powder resulted in a significant $(\mathrm{p}<0.05)$ dose dependant increase in cell migration (A), with maximal stimulation being seen at $1.0 \mathrm{mg} / \mathrm{ml}$ protein concentration. To analyse whether these effects were nonspecific, due to the presence of protein constituents, pro-migratory activity of the fish hydrolysate $(1 \mathrm{mg} / \mathrm{ml})$ was compared against cells incubated with a control protein, bovine serum albumin (BSA) at the same concentration (B). As the fish hydrolysate is likely to be taken orally, the effect of preincubating the product in acid and pepsin for one hour at $37^{\circ} \mathrm{C}$ on its ability to stimulate migration was determined. No loss of activity was seen (C). Data are presented as mean (SEM). ${ }^{* *} \mathrm{p}<0.01$, culture conditions caused a significantly greater increase in the distance migrated for all time points after four hours compared with cells grown in media alone.

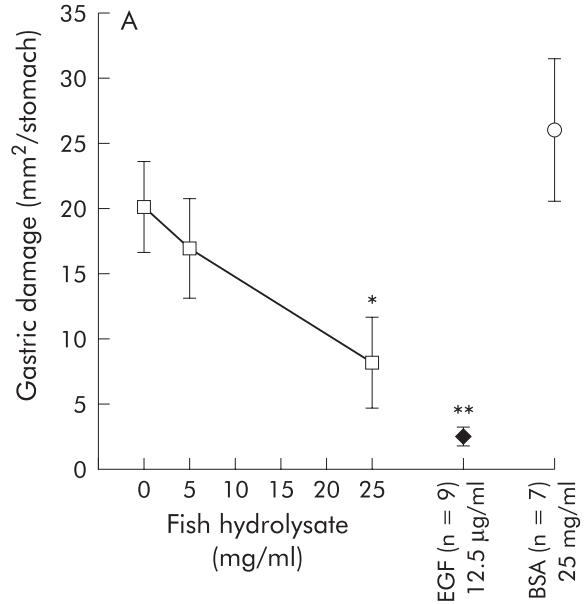

Gavage constitute (2 ml)

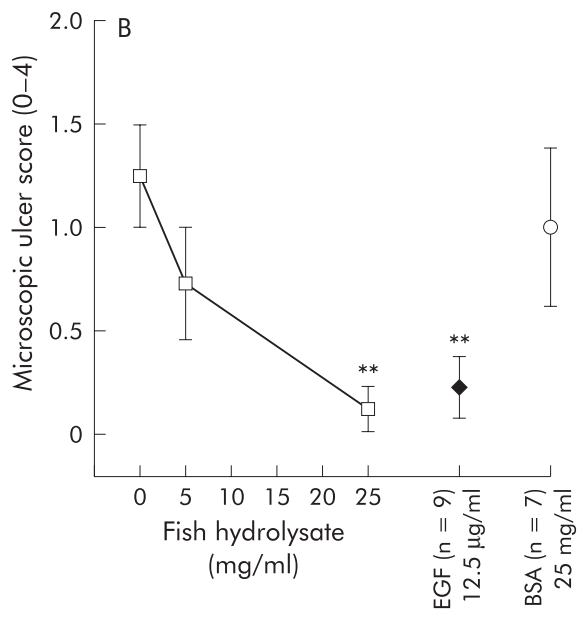

Gavage constitute (2 $\mathrm{ml})$

Figure 3 Effect of the fish protein hydrolysate on gastric injury. Rats were gavaged with $2 \mathrm{ml}$ of control solution (saline with $0.2 \mathrm{mg} / \mathrm{ml}$ bovine serum albumin (BSA)), fish hydrolysate at 5 and $25 \mathrm{mg} / \mathrm{ml}$, or epidermal growth factor (EGF, positive control) at $12.5 \mu \mathrm{g} / \mathrm{ml}$. A further group were given $25 \mathrm{mg} / \mathrm{ml}$ of BSA to determine specific from nonspecific effects of the fish hydrolysate. Rats were subsequently injected with indomethacin $(20 \mathrm{mg} / \mathrm{kg}$ subcutaneously) and placed in restraint cages. Three hours later, animals were killed and the degree of macroscopic (A) and microscopic (B) injury determined. Data are presented as mean (SEM) of $n=7-12$ per group. ${ }^{*} p<0.05,{ }^{* *} p<0.01$ versus control animals not given the fish hydrolysate, EGF, or BSA.

\section{RESULTS}

Study series A: effect of the fish protein hydrolysate on in vitro models of repair

Cell proliferation

Proliferation assays revealed a typical "bell-shaped" doseresponse curve (fig 1). Maximal activity of the fish protein hydrolysate was seen when utilised at a final concentration of $1 \mathrm{mg} / \mathrm{ml}$ in HT29 cells (fig 1A) and $0.1 \mathrm{mg} / \mathrm{ml}$ in RIE- 1 cells (fig 1B).

Cell migration as a model of wound repair

Addition of the fish powder to HT29 cells resulted in a significant $(p<0.05)$ dose dependant increase in cell migration. Maximal stimulation was seen at $1.0 \mathrm{mg} / \mathrm{ml}$ protein concentration (fig 2A). Higher doses did not enhance migration further (data not shown). Cells which had been incubated with the fish hydrosylate and proliferation inhibitor, mitomycin $\mathrm{C}$, showed a similar pro-migratory activity to that seen in wells incubated with fish hydrosylate 


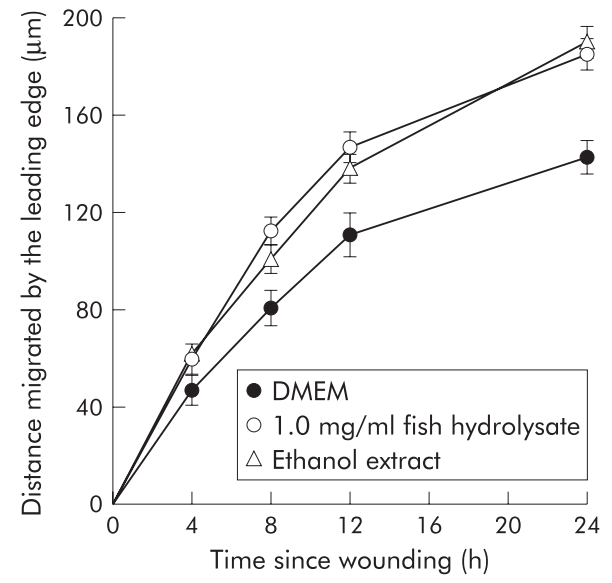

Figure 4 Investigation into active constituents within the fish protein hydrolysate: solubility into ethanol. Fish powder was mixed with 100\% aqueous ethanol and soluble substances and ethanol insoluble substances as residues were separated by decantation. Samples were dried on a centrifugal evaporator and re-suspended in Dulbecco's modified Eagle medium (DMEM) back to the original volume. The ability of this ethanol extract to stimulate cell migration was then compared against the original fish protein hydrolysate $(1 \mathrm{mg} / \mathrm{ml})$. Data are presented as mean (SEM).

alone, confirming that the restitutive effects seen were not dependant on cell proliferation (data not shown). To distinguish specific effects of hydrolysed white fish from non-specific effects of protein addition, the effect of adding BSA was tested when added at the same concentration. As can be seen (fig $2 \mathrm{~B}$ ), BSA only caused a minor pro-migratory effect.

\section{Study series B: stability of the bioactivity of the fish protein hydrolysate in acid/pepsin in vitro}

Preincubation with pepsin alone, $\mathrm{HCl}$ alone, or pepsin/ $\mathrm{HCl}$ (fig 2C) had no effect on the restitutive properties of the fish hydrolysate powder.

\section{Study series C: effect of the fish protein hydrolysate on an in vivo rat gastric damaging model}

Animals that received indomethacin and restraint and a placebo gavage had a mean macroscopic gastric damage score of $20(3.5) \mathrm{mm}^{2} /$ stomach. Administration of the fish protein hydrolysate caused a dose dependant reduction in the amount of gastric injury (fig 3A). This equated to a $16 \%$ reduction in those animals that had received $5 \mathrm{mg} / \mathrm{ml}$ of the hydrolysate and a 59\% reduction in animals that had received $25 \mathrm{mg} / \mathrm{ml}$ of the hydrolysate. Histological assessment using the microscopic scoring system gave similar results to those seen macroscopically (fig 3B). Administration of the fish hydrolysate at $25 \mathrm{mg} / \mathrm{ml}$ gave a gastric protective effect which was roughly similar to that seen in animals that had received the potent cytoprotective agent EGF at $12.5 \mu \mathrm{g} / \mathrm{ml}$ (fig 3). Gastric $\mathrm{pH}$ assessment showed that all of these effects were independent of alteration in $\mathrm{pH}$ (all gastric $\mathrm{pH}$ values were in the range 1-3). The reduction in gastric injury resulting from administration of the fish hydrolysate appeared to be a specific effect, as administration of an equivalent amount of BSA was ineffective in reducing the amount of injury (fig 3).

Study series $D$ : investigation into active constituents within the fish protein hydrolysate

Effect of ethanol extraction of fish protein hydrolysate on cell migration

The vast majority of the biological activity, as determined by following pro-migratory effects, was soluble in ethanol. A
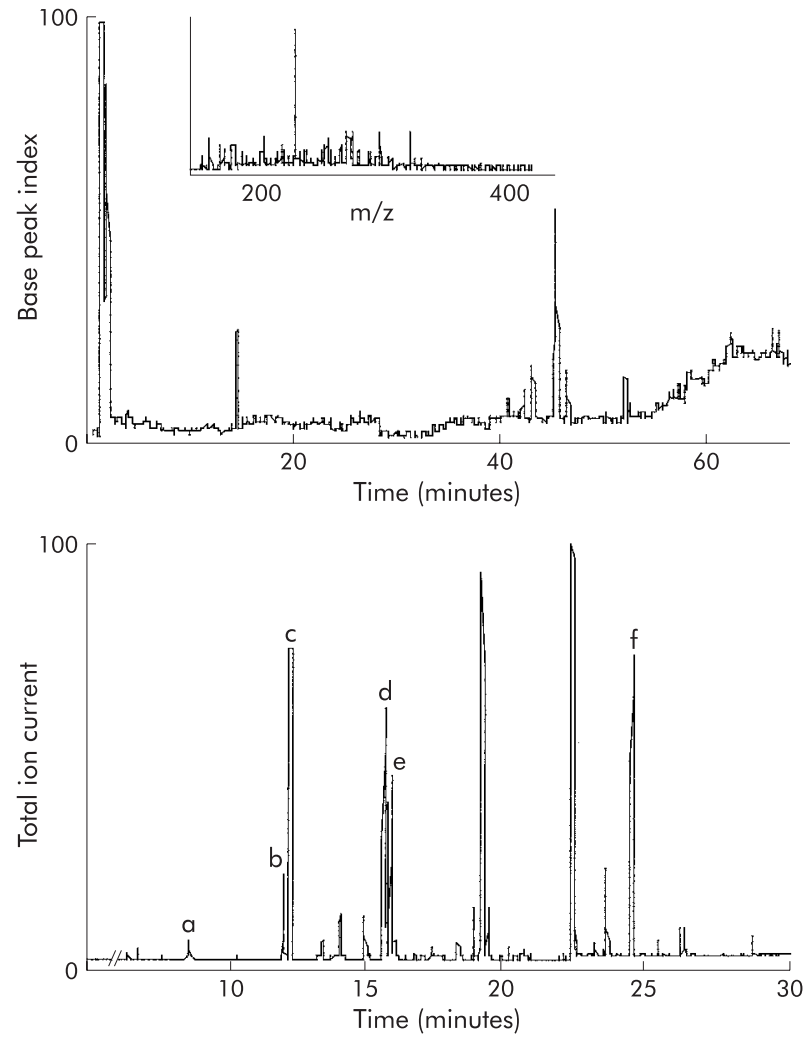

Figure 5 Investigation into active constituents within the fish protein hydrolysate: gas chromatography electron impact mass spectrometry and high pressure liquid chromatography (HPLC) positive ion mass spectrometry. The fish hydrolysate underwent ethanol extraction and was then subjected to HPLC positive ion mass spectrometry in order to analyse polar components (upper graph). A large early peak was seen and detailed analysis of this region (inset) showed it to contain multiple molecules with molecular weights of between 166 and $313 \mathrm{Da}$, in keeping with single amino acids and di and tripeptides. The ethanol extract was also analysed using gas chromatography electron impact mass spectrometry to determine lipophilic components (lower graph). As expected, the product contained a mixture of saturated and unsaturated fatty acids. Identified molecules included: (a) $\mathrm{Cl} 4: 0$, myristic acid;

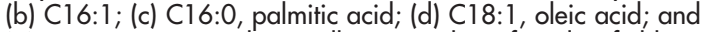
(e) C18:0, stearic acid, as well as a number of unidentifiable molecules. Peak $(f)$ is the plasticiser monoethyl hexyl phthalate which is a preparation artefact, but is useful for quality control.

typical result is shown in fig 4. Results from several studies showed that incubation of the fish hydrolysate in absolute ethanol for three hours resulted in approximately $73 \%$ of the activity transferring to the ethanol phase (data not shown).

\section{HPLC mass spectrometry and gas chromatography mass spectrometry}

As stated earlier, the ethanolic extract was examined by both HPLC positive ion mass spectrometry for the polar components and gas chromatography electron impact mass spectrometry for lipophilic components.

Reverse phase HPLC mass spectrometry of an aqueous: acetonitrile:formic acid (90:10:0.01) extract of the dried ethanolic sample showed a very large peak which eluted within the first 2-3 minutes (fig 5, upper graph). Detailed analysis of this zone showed that these polar compounds had masses consistent with single amino acids and di- and tripeptides (fig 5A inset) with molecular weights of 166, 227, $249,265,288,278,311$, and 313. A number of unidentified higher mass components were also present and eluted after this initial 2-3 minute peak (fig 5, upper graph). 


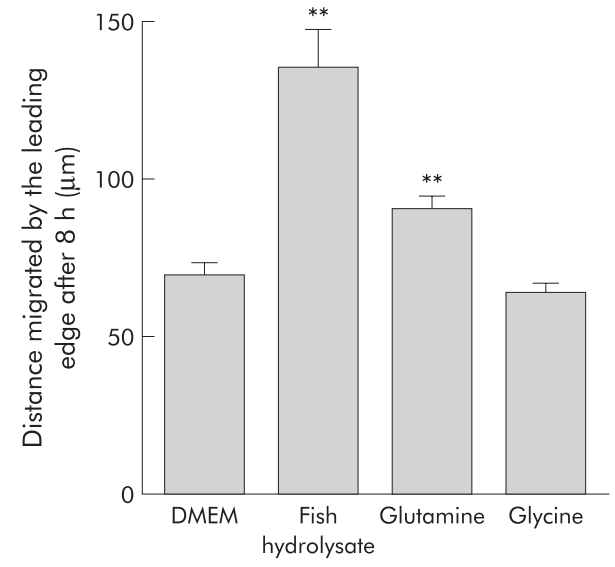

Figure 6 Comparison of the effect of glutamine and glycine on the rate of cell migration using an in vitro model of wound repair. To allow comparison across the different incubation conditions, the amount of cell movement eight hours after wounding is shown. Cells incubated with the fish hydrosylate at $1 \mathrm{mg} / \mathrm{ml}$ had an approximate doubling in the rate of movement compared with controls. Addition of glutamine, at a concentration equivalent to that found in the fish hydrosylate, showed that approximately $34 \%$ of this activity could be attributed to the glutamine in isolation. Addition of a control amino acid (glycine), at the same concentration as glutamine, did not stimulate cell movement above baseline. ${ }^{* *} \mathrm{p}<0.01$ versus Dulbecco's modified Eagle's medium (DMEM) control.

Gas chromatography mass spectrometry of an unsaponified sample showed the presence of numerous compounds: the major species present included a series of fatty acids (C14:0-C20:0), together with their unsaturated and monohydroxylated derivatives (C18:0-OH, C20:0-OH) (fig 5, lower graph). A number of compounds were not further characterised.

\section{Effect of glutamine on cell migration}

To allow easy comparison of the relative pro-restitutive effects of the different agents, fig 6 shows the absolute amount of cell movement that had occurred eight hours following induction of injury to the monolayers. Compared with controls, addition of the fish hydrosylate $(1 \mathrm{mg} / \mathrm{ml})$ caused an approximate doubling of the rate of movement. Cells grown in the presence of an equivalent amount of glutamine as that found in the fish hydrolysate $(1 \mathrm{mmol} / \mathrm{l})$ showed that about $34 \%$ of the total pro-migratory effect could be attributable to the glutamine added in isolation. However, addition of an equimolar amount of glycine (control amino acid, $1 \mathrm{mmol} / \mathrm{l}$ ) did not increase the migration of the leading edge above values found in the control.

\section{DISCUSSION}

We have shown that a commercially available fish hydrolysate preparation possesses both pro-migratory and proproliferative activity and is also able to reduce the degree of injury sustained in an in vivo rat gastric damaging model. We also showed that some, but not all, of these effects may be due to the relatively high concentrations of glutamine and glutamine containing peptides present within this product.

For the in vitro studies, rat small intestinal (RIE-1) and human colonic (HT29) cells were used to show that these effects were not species specific and to examine effects on cells from different regions of the bowel. Studies examining the potential beneficial effect of the fish hydrolysate on gastric injury were performed using indomethacin induced injury in rats, as we have previously validated this model for other bioactive agents such as bovine colostrum, ${ }^{4}$ and non-steroidal anti-inflammatory drugs, such as indomethacin, continue to be a major cause of morbidity and mortality in humans. ${ }^{6}$ Caution always has to be shown, however, in extrapolating results obtained from in vitro cancer cell lines and animal models to the human situation.

Mass spectroscopy provides a rapid sensitive method of determining the molecular weight of test molecules. In combination with HPLC, it is able to accurately determine the molecular weight of multiple polar constituents within complex samples such as the fish hydrolysate. We have previously used this method to examine partial cleavage of bioactive peptides, such as growth factors, within complex mixtures. ${ }^{7}$ Gas chromatography electron impact mass spectrometry provides a similar role for non-polar compounds. Although both of these methods provide highly accurate data with regard to molecular weight of compounds within such mixtures, it is important to note that they are not particularly useful for quantitative measurements where other techniques have to be used.

Hundreds, if not thousands, of products are currently marketed as "health food supplements"s; $72 \%$ of the American population use one or more health supplement products regularly and 57\% considered that these therapies reduced their need for drugs and other medical therapies. This results in an annual turnover of approximately $£ 1.4$ billion ( $\$ 2.4$ billion) in the UK and $£ 10$ billion ( $\$ 18$ billion) in the USA, with about an $8 \%$ annual growth. ${ }^{8}$ The sources of these "natural" products are diverse and include bacteria (for example, probiotics), plant (for example, prebiotics, herbal remedies), animal (for example, colostrum), insect (for example, honey), and marine (for example, sponges, snails) origins. A fuller review is provided by Ghosh and Playford. ${ }^{1}$ Unfortunately, current evidence of the scientific validity of most of these traditional and commercial compounds is severely limited and the level of evidence used in support of their claims often falling well below that acceptable in the medical and scientific community.

The fish hydrolysate studied in this article is already marketed in the USA as an "over the counter" health food supplement and, as with many of these products, its major marketing strategy is via patient validatory statements. There have, however, been some limited scientific studies. Englender reported that use of the fish protein hydrolysate, at a dosage of $3 \mathrm{~g} /$ day for 60 days, reduced the symptoms of occasional diarrhoea and constipation, and alleviated bloating. ${ }^{9}$ However, this study followed a self reporting questionnaire protocol and was not placebo controlled. Similarly, Thomas et al reported in abstract form, the results of a double blind placebo controlled study of the effect of taking a fish hydrolysate preparation on gut permeability, as assessed by lactulose/mannitol ratios, in a total of 15 patients with inflammatory bowel disease. Although the study showed some decrease in permeability in the fish hydrolysate treated arm, the change failed to reach significance and was possibly confounded by studying a mixture of Crohn's disease and ulcerative colitis patients with varying degrees of disease activity. ${ }^{10}$ It was because of this scarcity of firm data that we decided to investigate this product.

Our studies have shown bioactivity of this product in a variety of gut integrity and repair models. Factors present within the product influenced the early (restitution) and later (proliferative) responses as well as decreasing injury, via acid independent means, in the non-steroidal anti-inflammatory drug induced gastric injury model. Biological activity was retained following acid/pepsin incubation and was also shown to be present when administered orally to rats. This is important as, although biological activity of some food products may be demonstrated in vitro, this does not equate to activity once ingested. For example, many peptide growth 
factors present in food materials are susceptible to acid/ pepsin and pancreatic proteolytic digestion, and are therefore likely to be degraded to inactive forms soon after ingestion. ${ }^{7}$

The molecules responsible for these effects have been incompletely defined but do appear to be soluble in ethanol. Analysis of the bioactivity of glutamine within the product suggested this component played an important part although other undefined factors were also important. Glutamine has previously been shown to be trophic to several intestinal cell lines when tested at similar concentrations to the current study. ${ }^{11}$ In addition, the dipeptide alanyl-glutamine has also been shown to be pro-proliferative in vitro when used at a similar concentration. ${ }^{12}$ This dipeptide product is sometimes used in preference to glutamine, particularly for use in patients, as it is more stable during storage. This has relevance to the current study where much of the glutamine is likely to be present in the di- and tripeptide form. Although several studies have claimed beneficial effects of glutamine supplementation in animal or human situations involving injury, repair and bacterial translocation, particularly relating to the small and large intestine (for review see Ziegler and colleagues ${ }^{13}$ ), not all studies have shown positive effects (for example, Hulsewe and colleagues ${ }^{14}$ ) and its use in the clinical setting remains controversial.

Much of the amino acid constituents of the fish protein hydrolysate remain in the intact protein or partially cleaved form and it is possible that these intact proteins have direct bioactivity. In addition, partial digestion of naturally occurring proteins can result in the production of additional bioactive molecules. For example, the amidated beta-casomorphin morphiceptin Tyr-Pro-Phe-Pro-NH2 is an opioid peptide derived from partial digestion of bovine milk betacasein and, once produced, may well influence gut function. ${ }^{15}$

As stated earlier, the fish hydrolysate contains about $6-10 \%$ fish oils. A previous study by Ruthig and MecklingGill has shown that n-3 and n-6 fatty acids can stimulate cell migration in rat intestinal IEC-6 monolayers at concentrations (individual polyunsaturated fats tested at $30 \mu \mathrm{mol} / \mathrm{l}$ ) similar to those likely to be present in the fish hydrolysate. ${ }^{16}$ Although the pro-restitutive activity may be partially explained by the presence of these fatty acids, they are unlikely to be relevant to the pro-proliferative activity found in the current study as Ruthig and Meckling-Gill also showed that addition of these fatty acids actually reduced proliferation of IEC-6 cells. ${ }^{16}$

Indomethacin causes damage to the gastrointestinal tract by several mechanisms, including reduction of mucosal prostaglandin levels, reduction of mucosal blood flow, stimulating neutrophil activation, and possibly also stimulating apoptosis. ${ }^{17}$ It is likely that many of these mechanisms will be influenced by the numerous factors present in the hydrolysed fish preparation. For example, in addition to direct effects of bioactive peptides, glutamine constituents may have contributed to antioxidant activity via stimulation of glutathione production, and fatty acid constituents may have influenced the production of prostaglandins.

In conclusion, our studies have shown that a fish hydrolysate product, commercially available as an over the counter "health food" supplement for licensing purposes, possesses biological activity when assessed using several models of gut integrity and repair. It was able to induce the same biological repair promoting responses as the potent "drug" epidermal growth factor when tested in both the in vitro and in vivo situations. Although the absolute amount of fish hydrolysate required to induce these effects was about
$10^{3}$ higher than EGF, it is important to note that consumers are taking several grams of the fish hydrolysate per day (commercial suppliers recommend $1 \mathrm{~g}$, three times per day). Concentrations likely to be reached in human gastric juice are, therefore, likely to be at least as high as those used in the rat gastric damaging model $(5-25 \mathrm{mg} / \mathrm{ml})$. These results further emphasise that the division between "food products" and "drugs", when considered in terms of biological activity (and potential safety aspects), is far from clear and that this product should be considered as a "nutriceutical" or functional food. Further studies appear justified.

\section{ACKNOWLEDGEMENTS}

This work was partially funded under Wellcome Trust grant number 054787/B/98/Z and by Proper Nutrition, Inc., who are the manufactures of Seacure which was analysed in the current publication.

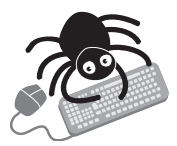

Conflict of interest: declared (the declaration can be viewed on the Gut website at http://www.gut.com/ supplemental).

\section{Authors' affiliations}

A J Fitzgerald, P S Rai, T Marchbank, S Ghosh, R J Playford, Department of Gastroenterology, Imperial College, Hammersmith Hospital Campus, London, UK

G W Taylor, Proteomics Department, Imperial College, London, UK B W Ritz, Department of Bioscience and Biotechnology, Drexel University, Philadelphia, PA, USA

\section{REFERENCES}

1 Ghosh S, Playford RJ. Bioactive natural compounds for the treatment of gastrointestinal disorders. Clin Sci 2003;104:547-56.

2 Farnworth ER, ed. Handbook of fermented functional foods. Boca Raton, Florida: CRC Press, 2003.

3 Playford RJ, Marchbank T, Chinery R, et al. Human spasmolytic polypeptide is a cytoprotective agent that stimulates cell migration. Gastroenterology
$1995 ; 108: 108-16$.

4 Playford RJ, Floyd DN, Macdonald CE, et al. Bovine colostrum is a health food supplement which prevents NSAID induced gut damage. Gut 1999;44:653-8.

5 Playford RJ, Vesey DA, Haldane S, et al. Dose-dependent effects of fentanyl on indomethacin-induced gastric damage. Digestion 1991;49:198-203.

6 MacDonald TM, Morant SV, Robinson GC, et al. Association of upper gastrointestinal toxicity of non-steroidal anti-inflammatory drugs with continued exposure: cohort study. BMJ 1997;315:1333-7.

7 Playford RJ, Marchbank T, Calnan DP, et al. Epidermal growth factor is digested to smaller, less active forms in acidic gastric juice. Gastroenterology 1995; 108:92-101.

8 Sloan AE. The top 10 Functional Food trends. Next Generation Food Technology 2002;56:32-57.

9 Englender C. Symptom reduction in irritable bowel syndrome with predigested fish protein supplement. Townsend Lett 2000;205/206:60-4.

10 Thomas PD, Nichols TW, Angstadt A. Dietary bioactive peptides in maintaining intestinal integrity and function. Am J Gastroenterol 2001; 96:S311.

11 Rhoads JM, Argenzio RA, Chen W, et al. L-glutamine stimulates intestinal cell proliferation and activates mitogen-activated protein kinases. Am J Physiol 1997;272:G943-53.

12 Scheppach W, Loges C, Bartram P, et al. Effect of free glutamine and alanylglutamine dipeptide on mucosal proliferation of the human ileum and colon. Gastroenterology 1994;107:429-34.

13 Ziegler TR, Bazargan N, Leader LM, et al. Glutamine and the gastrointestinal tract. Curr Opin Clin Nutr Metab Care 2000;3:355-62.

14 Hulsewe KW, Van Acker BA, Hameeteman W, et al. Does glutamine-enriched parenteral nutrition really affect intestinal morphology and gut permeability? Clin Nutr 2004;23:1217-25.

15 Mahe S, Tome D, Dumontier AM, et al. Absorption of intact betacasomorphins (beta-CM) in rabbit ileum in vitro. Reprod Nutr Dev 1989;29:725-33.

16 Ruthig DJ, Meckling-Gill KA. Both $(n-3)$ and $(n-6)$ fatty acids stimulate wound healing in the rat intestinal epithelial cell line, IEC-6. J Nutr 1999; 129:1791-8.

17 Levi S, Shaw-Smith C. Non-steroidal anti-inflammatory drugs: how do they damage the gut? Br J Rheumatol 1994;33:605-12. 